\title{
O programa residência pedagógica na perspectiva dos preceptores da área de ciências da natureza, na Universidade de Brasília
}

The pedagogical residency program in the natural science area preceptors point of view, in the University of Brasilia

Farah Camila Murtadha Ana Júlia Pedreira

Resumo: A formação docente pode ser dividida em inicial e continuada, sendo a primeira a graduação e a segunda qualquer processo formativo que venha ocorrer após essa. O Programa Residência Pedagógica (RP) foi realizado durante os anos de 2018 e 2019, auxiliando no processo de formação dos discentes de licenciatura, complementando os estágios supervisionados obrigatórios da Universidade de Brasília. Isso se deve ao fato de que, os estágios têm como maior foco, a regência, não dispondo de muito tempo para outras atividades extraclasse. O Programa Residência Pedagógica de 2018 totalizou 440h de imersão do residente, possibilitando o desenvolvimento de outras atividades essenciais para a futura prática docente favorecendo, assim, a formação dos licenciandos. O objetivo dessa pesquisa foi de investigar a percepção dos preceptores dos subprojetos da área de Ciências da Natureza, sobre o impacto do Programa na formação inicial de professores. Para isso, foram realizadas entrevistas semiestruturadas com os preceptores, seguidos de uma análise de conteúdo. Como resultados observou-se que todos os preceptores reconhecem que o Programa Residência Pedagógica colaborou para a formação dos residentes e reforçam que não foi unidirecional, ou seja, o Programa também acrescentou na formação continuada dos próprios. São apontadas, também, críticas, tais como o não esclarecimento de algumas informações e a falta de acompanhamento. Porém, conclui-se que, na visão deles, a RP trouxe vantagens para a formação docente como um todo, aspirando a continuidade do projeto, com futuros editais.

Palavras-chave: formação de professores, estágio supervisionado, residência pedagógica.

Abstract: Teacher's training can be divided into initial and continuing, with the first being undergraduate and the second any training process that may occur after this. Initial training programs, such as the Pedagogical Residence (PR), are carried out by universities, helping in the process of undergraduate students, complementing the supervised internships. This is because internships are mainly focused on regency, and don't have much time for other extra-classes activities. In the 2018 Pedagogical Residency Program notice, there were 440 hours of resident immersion, enabling the development of other essential activities for future teaching practice, favoring the training of these students. The purpose of this research was to investigate the perspective of preceptors of the subprojects in the area of Natural Sciences, about the impact of the Program in the initial training of teachers. For this, semi-structured interviews were conducted with the preceptors, followed by a content analysis. As a result, it was observed that all preceptors recognize that the PR collaborated for the training of residents and reinforce that it was not unidirectional, the Program also added to their continued training. It is also pointed out several considerations, such as the lack of clarification of some information and the lack of feedback. However, it is 
concluded that, in their view, the PR Program brought advantages to teacher's training, aspiring the continuity of the project, with future notices.

Keywords: teacher's training, supervised internship, pedagogical residency.

\section{Introdução}

\section{A formação inicial de professores}

O processo de formação do docente possui duas etapas principais: a formação inicial, que é desenvolvida durante a graduação (PACHECO, 1995) e a formação continuada, na qual considera-se qualquer formação após a graduação. Esta serve para aprimorar a prática do docente, podendo ser por meio de cursos, conferências, seminários e outras situações na qual o docente passa a ser o ouvinte (PACHECO, 1995; CUNHA; KRASILCHIK, 2000).

Mello (2000) e Gatti (2014) demonstram que a melhoria da formação inicial é indispensável quando se trata de otimizar a Educação Básica do país. Durante esse processo formativo é essencial que o discente tenha uma familiarização com a escola, para que o mesmo consiga refletir sobre a sua atuação como futuro docente e sobre a sua construção profissional, já que a profissão exige mais do que apenas pesquisas didáticas (PIMENTA, 1996; FLORES, 2010).

Nos dias atuais, a escola exige muito mais do que apenas um embasamento teórico, é necessário entender melhor a realidade da escola para que o professor consiga saber lidar com as mais variadas situações (GATTI, 2014). Essa familiarização com a escola inicia-se com os estágios supervisionados obrigatórios nos cursos de licenciatura, nesse momento, 0 discente acaba por se identificar, ou não, com a profissão, sendo as duas conclusões extremamente importantes, já que os estudantes da Educação Básica merecem um professor que "é professor" e não que "esteja professor" (SCALABRIN; MOLINARI, 2013). 


\section{Estágio supervisionado}

Segundo a Lei de Diretrizes Básicas da Educação Nacional (LDB) (BRASIL, 1996) os estágios supervisionados constam de atividades de prática pré-profissional, exercidas em situações reais de trabalho.

Para Gatti (2014) a maioria das universidades do Brasil têm seus estágios como atividades de observação, fator esse indispensável por proporcionar uma maior familiaridade com as turmas, podendo facilitar o planejamento (SCALABRIN; MOLINARI, 2013). Porém, a experiência com a prática é o que mais acrescenta ao discente, prática essa que vai além das regências, passando pela compreensão da realidade de seus alunos e tendo a consciência de que eles têm problemas como fome, violência, drogas, prostituição entre outros (SCALABRIN; MOLINARI, 2013).

Os estagiários, em geral, se sentem inseguros em sua primeira experiência nas escolas, apresentando nervosismo e dificuldades como controlar turmas mais indisciplinadas e ministrar suas aulas utilizando metodologias alternativas e, devido ao período curto dos estágios, os mesmos sentem dificuldades na realização de planejamentos (MARTINS, 2009; SCALABRIN; MOLINARI, 2013, SILVA; PEDREIRA, 2020). Já está descrito na literatura que há uma iniciativa em aprimorar o currículo dos cursos de licenciatura, visando uma maior imersão do estudante dentro das escolas (GATTI, 2014).

\section{Importância da imersão do discente na escola}

Programas de formação inicial como, por exemplo, o Programa Institucional de Bolsas de Incentivo à Docência (PIBID) têm sido implementados em várias instituições de Ensino Superior (GATTI, 2014), há pelo menos 10 anos. Criado pelo Decreto $n^{\circ} 7.219$, de 24 de junho de 2010 (BRASIL, 2010), o PIBID tem como principal objetivo aprimorar a prática docente de estudantes de licenciatura dando a oportunidade para o discente criar e participar de experiências metodológicas, tecnológicas e práticas docentes de caráter inovador e interdisciplinar (BRASIL, 2010). 
A importância da imersão de longo prazo, do discente, dentro de uma escola é demonstrado no trabalho de Quadros e Kochhann (2018), que estudaram um estágio com duração de 2 anos, em que os discentes realizaram monitorias, observações, além da prática docente. Neste estudo, os autores relatam que o contato com várias etapas da docência, sem a restrição à regência, contribuiu para uma melhor qualificação dos mesmos. A imersão também é importante para que o futuro docente consiga lidar melhor com as diferentes situações que ele possa vir a enfrentar (SCALABRIN; MOLINARI, 2013).

\section{O Programa Residência Pedagógica}

Através do Edital CAPES n 06/2018 (BRASIL, 2018) o Ministério da Educação lançou o Programa Residência Pedagógica (RP) como parte da Política Nacional de Formação de Professores. Esse programa é inédito no país e abrange desde a criação de uma Base Nacional Docente até a ampliação da qualidade e do acesso à formação inicial e continuada de professores da educação básica (BRASIL, 2017).

O Programa tem como objetivo principal reformular o currículo dos cursos de licenciatura, buscando aperfeiçoar os estágios curriculares supervisionados baseado em documentos realizados pelos próprios discentes participantes (BRASIL, 2018), além de proporcionar a imersão dos licenciandos na escola.

Para fazerem parte do Programa da Residência Pedagógica, as Instituições de Ensino Superior (IES) se inscreveram e participaram de uma seleção nacional. De acordo com o edital CAPES n 06/2018 (BRASIL, 2018) a carga horária da Residência Pedagógica era de 440 horas totais, o que corresponde a uma média de 10 horas semanais para o residente (discente que participa do Programa). Essas $440 \mathrm{~h}$ totais foram subdivididas em diferentes atividades (Figura 1). 
Figura 1. Fluxograma que mostra a distribuição de horas do programa de Residência Pedagógica, sendo realizadas durante 18 meses.

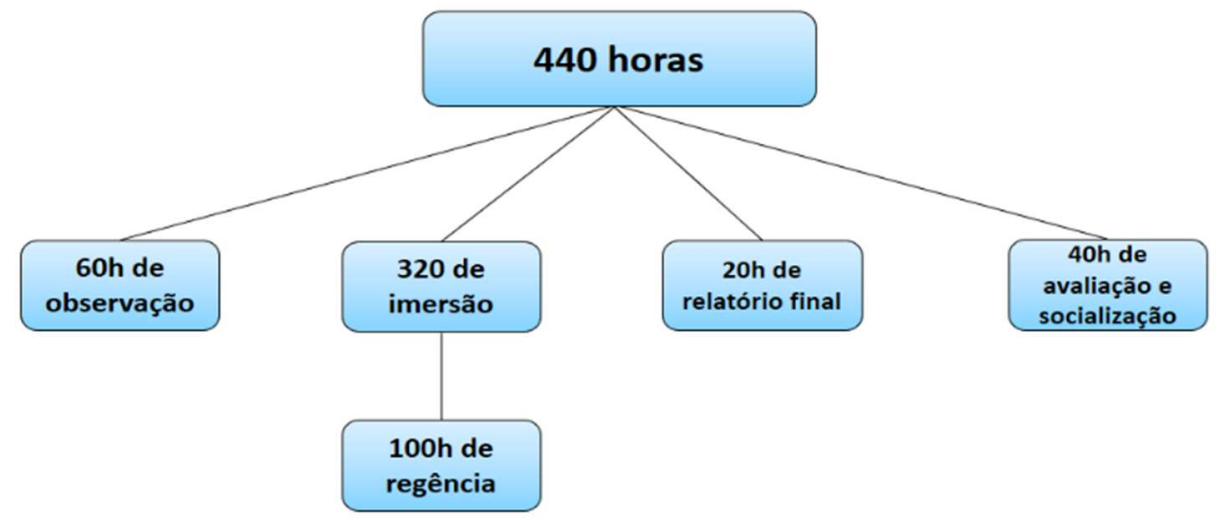

Fonte: Elaborado pelas Autoras

Os residentes do programa são encaminhados para as escolas da rede pública de Educação Básica, nas quais são chamadas, dentro do programa, de escola-campo. Para cada escola-campo há um preceptor, que é o responsável pelo acompanhamento dos residentes durante o projeto, dentro da escola. $\mathrm{Na}$ IES, o responsável por auxiliar os residentes e os preceptores e pela gestão do subprojeto é o docente orientador.

A efetividade do Ensino Básico depende da qualidade do profissional (BRASIL, 2017; BATISTA; LIMA, 2017) e no Brasil, de acordo com o Instituto Nacional de Estudos e Pesquisas Educacionais Anísio Teixeira (INEP) (2019), 77\% dos professores da Educação Básica do país possuem formação em licenciatura, sendo necessário otimizar esses dados, o que pode ocorrer pela melhoria de qualidade na formação inicial. Para isso, a implementação de projetos que incentivem a prática docente e a imersão do discente em licenciatura dentro da escola são essenciais.

Em 2014 entrou em vigor o Plano Nacional de Educação (PNE) (BRASIL, 2014) o qual visa a melhoria da Educação Básica como um todo. O PNE tem como uma de suas metas "fomentar a qualidade de educação básica em todas as etapas e modalidades, com melhoria do fluxo escolar e da aprendizagem [...]" (BRASIL, 2014, n.p.). Além de reforçarem que, para isso, é necessária uma melhora na qualidade da formação do professor da Educação Básica. 
O objetivo geral da pesquisa foi de investigar, por meio dos preceptores dos subprojetos da Residência Pedagógica da Universidade de Brasília (UnB), da área de Ciências da Natureza, as suas percepções sobre o impacto do projeto na formação inicial de professores. Os objetivos específicos foram verificar, pela percepção dos preceptores do Programa Residência Pedagógica da área de Ciências da Natureza da UnB, o que os motivou a participar do programa; examinar o que os preceptores da área de Ciências da Natureza do Programa Residência Pedagógica da UnB, achavam do Programa até o momento da realização da pesquisa; compreender, pela percepção dos preceptores do Programa Residência Pedagógica, como esse auxilia na formação inicial dos discentes de Licenciatura; investigar se a participação do preceptor no programa vem de alguma forma alterando sua prática docente e se sim, como e por fim verificar se os preceptores possuem sugestões para a melhoria do Programa Residência Pedagógica.

\section{Metodologia}

Essa pesquisa se caracteriza pela abordagem qualitativa, a partir da realização de entrevistas com professores do Ensino Fundamental II e Ensino Médio da rede pública, ainda durante o período de realização do Programa Residência Pedagógica. Esses preceptores orientavam entre 8 e 10 residentes do Programa Residência Pedagógica da Universidade de Brasília (UnB) e atuavam em escolas localizadas no Distrito Federal. O Programa Residência Pedagógica da UNB teve início no mês de setembro de 2018 sendo finalizado no mês de janeiro de 2020. Participaram do Programa oito subprojetos: Biologia, Ciências Naturais, Física, Português, Geografia, Filosofia, Artes Cênicas e Música. Para essa pesquisa foram selecionados apenas os preceptores da área de Ciências da Natureza. Os subprojetos eram coordenados pelos docentes orientadores da universidade, que se reuniam periodicamente com os residentes para planejamentos e estudos. Na escola os preceptores recebiam os estudantes e, juntos, discutiam os planejamentos e decidiam as atividades que cada um deles seria responsável por realizar. 


\section{Preceptores}

Para participar da pesquisa, os preceptores deveriam atuar nos subprojetos ligados à área de Ciências da Natureza (Física, Ciências Naturais e Biologia, uma vez que não havia subprojeto de Química), do Programa Residência Pedagógica da UnB. Os preceptores foram escolhidos para colaboração deste projeto devido ao seu vínculo com a escola e por estarem acompanhando diretamente os residentes no decorrer do projeto. Para cada subprojeto, havia três preceptores. Em um subprojeto, um dos preceptores não acompanhou os residentes desde o início das regências, assim, os pesquisadores optaram por entrevistar apenas dois preceptores por subprojeto. Para preservar a identidade de todos os preceptores e de todas as instituições, foi dado um código (Quadro 1).

Quadro 1. Códigos dos preceptores e sua respectiva escola de atuação.

\begin{tabular}{|l|l|}
\hline Preceptor & Escola \\
\hline P1 & E1 \\
\hline P2 & E2 \\
\hline P3 & E3 \\
\hline P4 & E4 \\
\hline P5 & E5 \\
\hline P6 & E5 \\
\hline
\end{tabular}

Fonte: Elaborado pelas Autoras

\section{Instrumento de pesquisa e análise dos dados}

Nesta pesquisa foram realizadas entrevistas semiestruturada. Esse tipo de entrevista, segundo Duarte (2004), permite uma discussão mais flexível. As entrevistas foram gravadas, com autorização prévia dos participantes e posteriormente transcritas.

Após a transcrição seus conteúdos passaram por uma análise de conteúdo seguindo o modelo de categorização/agrupamento utilizando pontos chaves (BARDIN, 2006). Para isso, existem duas maneiras, a primeira é a 
categorização iniciando-se pela visão geral e finalizando pela visão específica. Essa categorização possui um "tema" mais amplo, na qual as outras informações específicas se encaixam nele. O segundo método inicia-se pelos elementos particulares na qual se divergem em um elemento mais amplo na qual tornaria o título da categoria (BARDIN, 2006). A autora do presente trabalho optou pelo segundo método de categorização.

\section{Entrevistas}

Todas as entrevistas foram realizadas na própria escola onde os preceptores atuam, no dia e horário escolhido pelos preceptores. Diferente dos demais, onde as entrevistas foram individuais, os preceptores do subprojeto de Ciências Naturais foram entrevistados juntos, por ação deles. Anterior à realização da entrevista foi entregue um Termo de Consentimento e Livre Esclarecido (TCLE).

Nas entrevistas foram levantadas as seguintes questões estruturantes:

O que te motivou a entrar para o Programa Residência Pedagógica?

O que você vem achando do Programa Residência Pedagógica?

Você acha que o Programa Residência Pedagógica interfere na formação inicial dos discentes de licenciatura? Justifique sua resposta.

Você acha que participar do Programa Residência Pedagógica vem mudando sua prática docente? Justifique.

Sugestões para a melhoria do Programa Residência Pedagógica.

\section{Categorização e análise de dados}

As categorias foram definidas após a leitura do material transcrito. Durante a leitura do material foi percebida uma forte relação entre as questões realizadas, dessa forma, optou-se por fazer uma discussão única sem se restringir a elas. As falas foram analisadas e categorizadas conforme apresentado no Quadro 2. 
Quadro 2. Categorização da fala dos preceptores seguida de uma breve descrição.

\begin{tabular}{|c|c|c|}
\hline Tópicos & Categorias & Descrição \\
\hline $\begin{array}{l}\text { Incentivo para a } \\
\text { participação do Programa } \\
\text { Residência Pedagógica }\end{array}$ & Distanciamento & $\begin{array}{l}\text { Falta de conversa entre Universidade } \\
\text { e Escola. Como o Programa RP } \\
\text { diminui esse distanciamento? }\end{array}$ \\
\hline $\begin{array}{ll}\text { Perspectiva dos } & \text { do }\end{array}$ & Projetos & $\begin{array}{l}\text { Quais projetos que os residentes } \\
\text { estão desenvolvendo na escola. }\end{array}$ \\
\hline $\begin{array}{l}\text { preceptores em relação ao } \\
\text { Programa } \quad \text { Residência } \\
\text { Pedagógica }\end{array}$ & Relacionamento & $\begin{array}{l}\text { A relação dos residentes com a } \\
\text { escola como um todo (funcionários, } \\
\text { alunos, outros professores, o } \\
\text { preceptor). }\end{array}$ \\
\hline & Vivência & $\begin{array}{l}\text { A vivência como ponto principal na } \\
\text { formação inicial dos discentes de } \\
\text { licenciatura. }\end{array}$ \\
\hline $\begin{array}{l}\text { na formação inicial dos } \\
\text { discentes de licenciatura }\end{array}$ & $\begin{array}{l}\text { Estágio } \\
\text { Supervisionado } \\
\text { Obrigatório }\end{array}$ & $\begin{array}{l}\text { Diferenças entre o Programa de } \\
\text { Residência } \\
\text { Estágios }\end{array}$ \\
\hline $\begin{array}{l}\text { Formação continuada de } \\
\text { professores }\end{array}$ & Informações & 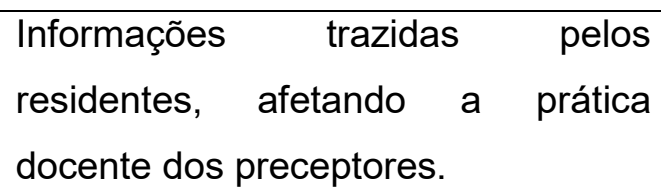 \\
\hline \multirow{4}{*}{$\begin{array}{lll}\text { Elogios, } & \text { críticas } & \text { e } \\
\text { sugestões } & & \end{array}$} & Elogios & $\begin{array}{l}\text { Elogios sobre o Programa de } \\
\text { Residência Pedagógica. }\end{array}$ \\
\hline & Falta de instruções & $\begin{array}{l}\text { A falta de instruções como sendo } \\
\text { uma crítica ao Programa Residência } \\
\text { Pedagógica. }\end{array}$ \\
\hline & $\begin{array}{l}\text { Falta de } \\
\text { acompanhamento }\end{array}$ & $\begin{array}{l}\text { A falta de acompanhamento como } \\
\text { sendo uma crítica ao Programa } \\
\text { Residência Pedagógica. }\end{array}$ \\
\hline & Sugestões & $\begin{array}{l}\text { Sugestões dos preceptores para o } \\
\text { Programa Residência Pedagógica. }\end{array}$ \\
\hline
\end{tabular}

Fonte: Elaborado pelas Autoras 


\section{Resultados e discussão}

Todos os seis preceptores entrevistados participaram do programa Residência Pedagógica desde o início do mesmo, com à exceção de uma preceptora do subprojeto de Ciências Naturais que entrou para o programa após um semestre do seu início, não participando da fase de ambientação dos residentes.

\section{Incentivos para a participação no Programa Residência Pedagógica}

Foi possível observar, na fala dos preceptores, dois principais incentivos para o ingresso no Programa Residência Pedagógica, sendo elas: a aproximação das universidades em relação às escolas além de uma expectativa em "recarregar" a sua motivação dentro da secretaria de educação.

Um dos preceptores entrevistados participou do PIBID durante a sua graduação, vivenciando a experiência de um programa de formação docente. Alguns pontos positivos do PIBID são relatados por Trevisan et al. (2016) que trazem em seu trabalho a importância e a oportunidade dos discentes de licenciatura em conviverem com o professor efetivo da escola, demonstrando que há uma troca de experiência, principalmente no que se refere ao que o mesmo já vivenciou durante o seu período de docência. Ideia essa reforçada por um dos preceptores:

"Se eu posso ensinar um menino de 15 anos, por que eu não posso ajudar uma pessoa de 20 anos que quer ter a mesma profissão do que eu?" (P1).

É possível perceber na fala acima, que o preceptor P1 reforça essa ideia de troca de experiência. Para uma formação de qualidade, é interessante que haja um acompanhamento, fazendo com que o profissional em formação consiga se aproximar da realidade que irá enfrentar, além de poder ajudar o professor em atividade com eventuais problemas (SILVA; OLIVEIRA, 2016; BISPO; SOARES, 2017). O preceptor P1 ainda reforça outro ponto positivo desse convívio:

"Infelizmente a universidade não vem à escola. Ela tem lá seus professores com seus doutorados falando como tem que ser, 
mas quem está aqui na escola todos os dias sou eu. Então quando a gente faz um programa como a Residência Pedagógica, a gente traz a universidade para cá. [...] Esses alunos (discentes) têm que estar ao máximo dentro da escola." (P1)

É importante ressaltar na fala do preceptor acima, que os residentes trazem uma maior aproximação entre a universidade e a escola. Segundo Harres, Wolffenbuttel e Delor (2016) para as universidades, as escolas costumam demandar muito dos professores fazendo com que esses não tenham tempo disponível para realizar os cursos e outras atividades que são oferecidas para a formação continuada. Já para as escolas, os projetos das universidades não têm muita coerência com a rotina escolar, alegando não acrescentar na prática docente (HARRES; WOLFFENBUTTEL; DELOR, 2016). Além disso, é importante que as universidades realizem mais projetos de ensino, pesquisa e extensão a fim de auxiliar a formação de professores (DOURADO, 2015), já que existem relatos sobre trabalhos cooperativos, entre as escolas e as universidades, trazendo resultados positivos (BRITO; SOARES, 2017).

Esse distanciamento ocasiona, também, uma falta de motivação, no ponto de vista de $33 \%$ dos preceptores, que estão na carreira por mais de 10 anos. Além de fatores como a falta de recursos como materiais pedagógicos e estrutura, o desinteresse dos estudantes e a desvalorização dos professores por parte dos funcionários das escolas e dos pais (SOUZA; PAIXÃO, 2015; NASCIMENTO; RODRIGUES, 2018). Na fala de um dos preceptores é relatado que "[...] mesmo nessa situação, os residentes estão animados. Eles dão essa injeção de ânimo" (P3), incentivando os professores e melhorando a sua prática docente, o que pode auxiliar muitos professores.

\section{Perspectiva dos preceptores em relação ao Programa Residência Pedagógica}

Foi possível observar na fala dos preceptores alguns fatores positivos, como a realização de projetos dentro das escolas e a boa convivência entre aqueles que participam diretamente do projeto. 
De acordo com $83 \%$ dos preceptores, os residentes apresentaram bom desenvolvimento ao longo do projeto destacando: "Grande parte das minhas expectativas estão sendo cumpridas" (P2) e "O projeto me surpreendeu positivamente" (P3). O preceptor P3 reforça ainda, que os residentes "encaram a Residência Pedagógica como um trabalho" (P3). Os preceptores, de forma geral, se sentem bastante satisfeitos com o Programa.

Para $50 \%$ dos preceptores a presença dos residentes na escola os possibilitaram realizar projetos pedagógicos. Os mesmos apontam que há uma grande dificuldade em planejá-los e realizá-los, mas os residentes que acabam ficando responsáveis pelos mesmos, como destacado na fala a seguir:

"A Residência Pedagógica nos permite pensar em projetos que eu nunca havia pensado antes. Além de que, quem toca os projetos são eles (residentes) e não eu (preceptor), então sem eles, nada disso seria possível." (P4)

É possível perceber na fala do preceptor acima que existe uma colaboração entre os residentes e o próprio preceptor, na perspectiva de melhorar a dinâmica da escola com os projetos. Lopes et al. (2016) afirma que a qualidade daquilo que está sendo desenvolvido é aprimorada a partir do momento em que existe uma cooperatividade entre àqueles que 0 desenvolvem.

Durante a entrevista foram relatados alguns projetos que estavam em andamento ou em planejamento, por exemplo, a organização do laboratório da escola com a produção de modelos e jogos didáticos realizado pelo subprojeto de Biologia, uma palestra sobre Física Nuclear ministrada pelo próprio residente do subprojeto de Física e o projeto de levar o planetário para a escola que estava sendo planejado pelo subprojeto de Ciências Naturais. Batista, Lavaqui e Salvi (2016) mostram a importância de projetos dissertando que eles funcionam como "orientadores" para o processo pedagógico dos estudantes. Porém, a implementação de projetos nas escolas apresenta dificuldades, principalmente quando envolve novas tecnologias, porque alguns professores não se sentem à vontade em realizar algo na qual não são familiarizados (VIEIRA; BAPTISTA, 2015). Sendo assim, a presença dos residentes na escola 
contribuiu, na perspectiva dos preceptores, para o desenvolvimento dos projetos.

Para aproximadamente $83 \%$ dos preceptores os residentes, ao longo do programa, criaram um grande vínculo com todos que participam no projeto, como os funcionários das escolas, os próprios preceptores e principalmente os estudantes. Para $66 \%$ dos preceptores, a proximidade dos residentes com os estudantes acarretou uma maior proximidade deles com a disciplina que estavam ministrando. Um dos preceptores destaca um momento específico:

\begin{abstract}
"Durante uma atividade que estávamos fazendo [...] a maioria das meninas só tiravam dúvidas com a residente (mulher) [...] elas até me olhavam um pouco preocupadas, [...] já que, estatisticamente, há uma maioria de professores homens, até mesmo aqui na escola, [...] e eu achei isso muito legal. Para mim, o ganho maior foi essa identificação que as alunas tiveram com essa residente." (P1).
\end{abstract}

A partir dessa fala pode-se observar que, os estudantes aproveitaram a presença dos residentes nas escolas, se aproximando deles e da disciplina.

Relatos de $33 \%$ dos preceptores demonstram que os próprios residentes se sentiram à vontade com a comunidade escolar. Um deles menciona que há um residente que estudou na escola em que realizou o Programa tendo, assim, muito mais do que um vínculo profissional. Para Rodrigues e Garms (2013) ter um vínculo afetivo durante o processo de aprendizagem é importante, pois esse vínculo pode "dar suporte" no desenvolvimento dessa aprendizagem. 0 afeto do residente pela escola, reflete também nos estudantes, ratificando que os professores têm contato com outras pessoas e que é possível uma troca de experiência emocional entre eles e os estudantes, e não somente prover de conteúdos escolares (RODRIGUES; GARMS, 2013).

O vínculo emocional criado por pessoas que convivem diariamente é necessário, tornando o ambiente de convívio mais confortável, o que pode fazer com que as pessoas presentes adquiram uma maior motivação.

\title{
A Residência Pedagógica na formação inicial de professores
}

Os preceptores apontam que o projeto como um todo trouxe vários benefícios para os discentes de licenciatura. São feitas comparações com o 
estágio supervisionado e destacam a principal vantagem do programa: a vivência do discente dentro da escola, já que na percepção da maioria dos preceptores, o tempo em que o discente de licenciatura passa na escola não é suficiente.

O preceptor P6 aponta que os residentes, diferentemente dos estagiários, conseguem "acompanhar o progresso (dos estudantes), ver as dificuldades e propor soluções" (P6). Há um consenso entre os preceptores entrevistados de que somente o estágio não cumpre com o objetivo de preparar o licenciando. O preceptor P1 reforça que o estágio "não te faz preparado para encarar 40 alunos, 40 histórias diferentes, 40 sofrimentos diferentes" (P1). O que mostra a preocupação que o preceptor tem em mostrar aos discentes que ser docente vai além de dar aula, é entender a realidade dos próprios alunos. Essas falas corroboram com os trabalhos de Pires et al. (2015) e Auarek e Viseu (2017) as quais demonstram que, o maior contato com os estudantes permite a capacidade de entender melhor a realidade dos mesmos, tornando o docente mais crítico em relação as próprias atitudes frente a eles.

Mesmo a carga horária dos estágios obrigatórios tendo sido ampliada para quatrocentas horas, pela Resolução CNE/CP 2 (BRASIL, 2002) se aproximando das horas totais exigidas pelo Programa Residência Pedagógica (BRASIL, 2018), 50\% dos preceptores reforçam que os estágios não focam em todas as atividades que compõe a prática docente. Santos, Vieira e Santos (2018) e Hartmann e Goi (2019) demonstram em seus trabalhos que os estágios supervisionados têm como principal objetivo aprimorar a regência dos futuros professores e demonstram que essa regência envolve tudo aquilo que direciona o estagiário para a docência em sala de aula.

Cerca de $83 \%$ dos preceptores relatam que durante o Programa os residentes realizaram o planejamento pedagógico, participam de conselhos de classe, reunião de professores, reunião de pais, entre outras atividades dentro das escolas. Dessa forma, os residentes têm a oportunidade de vivenciarem os problemas e as dificuldades que possam vir a ocorrer nas escolas. Bisconsini e Oliveira (2018) reforçam que "Ser professor [...] envolve as relações profissionais com pais, alunos, diretores, pedagogos [...] é trabalhar em escolas 
com diversos materiais e em outras sem estrutura" (p. 12). Os mesmos autores afirmam ainda que, ter o máximo de contato com a realidade durante o período de graduação minimiza a complexidade das situações, o que prepara melhor o futuro docente. Ainda em relação a isso, um preceptor afirmou que, apesar de cada experiência vivida seja diferente, já é extremamente vantajoso para um licenciando sair da graduação com "parte dos desafios, parte de tudo aquilo que envolve a prática docente" (P2). Fala essa que corrobora com o trabalho de Bispo e Soares (2017), quando tratam da importância de vivenciar a escola, para que os discentes consigam refletir e saibam lidar com situações que poderão vir a ocorrer.

Além de conhecer a realidade em que irão atuar, um preceptor reforça a importância dessa vivência fazendo uma analogia ao retirar habilitação de trânsito:

"Você só aprende a dirigir mesmo quando você está no eixão (uma via de Brasília), está chovendo e todo engarrafado e o farol queima, ou seja, essa imersão, ela é a grande chave da Residência." (P1)

Vale ressaltar que o mesmo aponta que essa imersão envolve mais do que apenas um "passar o tempo" dentro da escola e, sim, se envolver em todas as atividades que ocorrem na mesma. O tempo de imersão dos residentes nas escolas também faz com que o discente de licenciatura tenha certeza de que quer seguir ou não com a carreira docente: "É aquela história né, ou ama, ou odeia..." (P3). Para esse preceptor, aqueles que possuem a verdadeira noção do que o profissional convive em seu dia-a-dia, ou acaba desmotivado e então desiste da carreira, ou se sente mais motivado a continuar. Fato esse que corrobora com o trabalho de Scalabrin e Molinari (2013) no que se refere à identificação com a profissão, citando que "é esse o momento que o acadêmico se vê professor e avança ou recua" (p. 11).

Portanto, o tempo de imersão do discente na escola não é o mais importante para a sua formação inicial e sim por permitir vivenciar toda a dinâmica da escola adquirindo, assim, maior quantidade de experiência possível. Caso o estudante de licenciatura decida mesmo pela docência, esse poderá se sentir mais preparado. 


\section{Formação continuada dos professores preceptores}

Todos os preceptores afirmam que o Projeto Residência Pedagógica vem acrescentando experiência à sua prática docente. É possível observar que os residentes trazem informações que acrescentam e otimizam a regência do próprio preceptor.

Um dos preceptores estava realizando o seu mestrado durante o período em que foi entrevistado e fez comparações deste com a Residência Pedagógica, apontando que "o mestrado é muito teórico" (P3), enquanto os residentes trazem consigo, muitas atividades práticas. A formação continuada de professores é essencial (CORREA et al., 2017; COSTA, 2019) para lidar com as dificuldades enfrentadas nas escolas e, principalmente, porque o que define a qualidade de um docente não é o domínio de conteúdo e sim a sua didática (COSTA, 2019).

Para $50 \%$ dos preceptores os residentes trazem informações, principalmente a respeito de atualizações. Esses preceptores citam que, como a área de Ciências Naturais está em constante mudança, é sempre importante ter conhecimento das novas informações. Acrescentam ainda que quem traz essas novidades são os próprios residentes, já que os mesmos ainda estão cursando a universidade e, portanto, encontram-se mais próximos dos professores que realizam pesquisas. As atualidades podem muitas vezes auxiliar o professor a relacionar o conteúdo dado em sala de aula com a realidade dos estudantes, aproximando-o do tema estudado. Silva e Oliveira (2016) reforçam dizendo que instigar o estudante a ver uma aplicabilidade do conteúdo em seu cotidiano torna o ensino "mais atraente" e "significativo", contribuindo para o seu aprendizado (SILVA; OLIVEIRA, 2016, p.12). Um dos preceptores destaca que as informações trazidas pelos residentes ampliam não somente os conhecimentos dos estudantes, mas também a compreensão do docente:

"Já que cada um tem um conteúdo que mais domina, eles acabam por enriquecer muito as aulas, trazendo informações que eu mesma, não traria para as minhas aulas, então isso não acrescenta somente para os estudantes, mas para a gente que está ali assistindo a aula daquele residente"(P5). 
A fala do preceptor acima é corroborada por Flores (2016), quando afirma que o compartilhamento de informações profissionais valoriza $\circ$ ambiente de trabalho. É necessário o professor permitir-se a novos conhecimentos que possibilitem trocas de experiências, o olhar sobre as necessidades do outro, podendo, assim, favorecer uma prática pedagógica diferenciada e adequada a cada particularidade (MARCHI; SILVA, 2016).

São entre 8 a 10 residentes atuando em cada escola, dessa forma, a troca de informações é bastante ampla, além de enriquecer as regências, não há uma sobrecarga, mas sim cooperação. Trazer essas informações auxilia o próprio professor que, muitas vezes têm dificuldade em ir em busca delas, devido a vários fatores, como principalmente a desmotivação, o que reforça a importância dos residentes.

\section{Elogios, críticas e sugestões}

Todos os preceptores fizeram elogios ao programa, porém, a maior crítica foi a falta de acompanhamento e de instruções claras. Aproximadamente $83 \%$ dos preceptores relataram que o Programa Residência Pedagógica superou muito as expectativas criadas antes do início do programa. Relatos do preceptor P6 apontam que os residentes eram reconhecidos pelos estudantes e pelos funcionários como parte da escola. Esteves et al. (2015) relata que, quanto maior o acompanhamento, em relação ao trabalho realizado, sendo esse desenvolvido no mesmo ambiente, facilita o reconhecimento, dando espaço para uma maior valorização do profissional.

Outro ponto destacado foi também o fato de que, como são muitos residentes, todos acabam se ajudando, deixando assim as aulas e os planejamentos bem mais dinâmicos e uma menor preocupação/sobrecarga para o professor. Para Machado (2007) e Costa (2016) a sobrecarga de trabalho na escola afeta a saúde pessoal dos professores, assim, os autores trazem que a divisão de trabalho é uma solução para minimizar essa sobrecarga.

Apesar dos elogios em relação ao programa, $50 \%$ dos preceptores apontam que a falta de instruções e esclarecimento de algumas informações foi 
um incômodo que perdurou durante o Programa, até o momento da entrevista. Cerca de $33 \%$ dos preceptores relataram dificuldades em relação à compreensão das atividades que deveriam ser desenvolvidas na regência, por exemplo, e disseram que um maior esclarecimento ou até mesmo uma padronização prévia dessas informações seria algo extremamente importante. A falta de informações dessa natureza deixou os preceptores bastante aflitos, devido à preocupação em relação aos residentes estarem sendo sobrecarregados por excesso de horas trabalhadas nas escolas.

Uma das maiores críticas, para os preceptores, foi falta de acompanhamento por parte dos docentes orientadores das IES. Para $50 \%$ a falta de presença dos coordenadores e a falta de uma comunicação mais constante entre os preceptores, foi um ponto negativo do programa, já que muitos se sentiram perdidos em alguns momentos. Eles apontam que houve uma necessidade de uma maior comunicação entre os participantes do Programa como um todo. Silva, Teixeira e Rodrigues (2016) demonstram em seu trabalho, que o acompanhamento dos coordenadores em projetos realizados dentro das escolas foi essencial para a otimização desses.

No primeiro semestre de 2019 ocorreu uma reunião geral que reuniu todos os preceptores de todos os subprojetos do Programa Residência Pedagógica. Nessa reunião houve palestras sobre o programa e sua criação e a comparação dele com o PIBID. Como as falas dos palestrantes foram longas, não houve oportunidade para a fala dos preceptores, sendo essa a principal indignação demonstrada pelos entrevistados. Assim, reuniões mais constantes entre preceptores e coordenadores da IES, permitindo uma maior troca de experiência foi sugerida por $50 \%$ dos preceptores entrevistados. Lopes et al. (2016) apontam em seu trabalho que, a otimização da aprendizagem de forma geral, é realizada pelas interações nas quais os sujeitos possuem tanto entre eles mesmos quanto com o objeto.

Para um preceptor, a necessidade da troca de experiência serve para entender a dinâmica das outras escolas e outros subprojetos para que essas sejam acrescentadas à sua própria realidade. Vieira e Baptista (2015) e Bedin e Pino (2019) relatam que a falta de comunicação entre os docentes, acarreta a 
diminuição na eficiência do trabalho docente. Para Vilela e Melo (2017), quando há um compartilhamento de experiências entre docentes, independentemente da área de atuação, há um desenvolvimento de novas metodologias para que a prática pedagógica dos docentes sofra melhoras consideráveis.

Além disso, por existir na mesma IES três subprojetos de Ciências da Natureza, a troca de experiências pode ser intensificada fazendo com que projetos pedagógicos possam ser compartilhados, otimizando, assim, o desenvolvimento dos subprojetos e do programa como um todo. Lima e Fialho (2015) e Leite e Pinto (2016) relatam em seus trabalhos sobre a importância da comunicação entre os profissionais da mesma área, principalmente afirmando que os profissionais que realizam essa prática sentem menos dificuldades em seus trabalhos e sendo esse um ótimo exercício docente.

Para os preceptores de Ciências da Natureza, da Universidade de Brasília, o programa ainda precisa ser lapidado, para que assim seja otimizado e possa se tornar uma referência para a formação inicial de professores. Secco, Rebeque e Souza (2017) demonstram que projetos de formação inicial são importantes e que aperfeiçoá-los é necessário, sugerindo, assim, que haja um acompanhamento por meio de pesquisas.

Os preceptores entrevistados acreditam que o Programa Residência Pedagógica tem um grande potencial para continuar e reforçaram, durante toda a entrevista, os seus pontos positivos, demonstrando-se bastantes satisfeitos. Até a finalização das entrevistas não havia sido publicado um novo Edital para implementação do Programa Residência Pedagógica, o que só ocorreu em janeiro de 2020, através do Edital $n^{\circ} 1 / 2020$ CAPES (BRASIL, 2020)

\section{Considerações finais}

Observou-se nessa pesquisa que todos os preceptores viram no Programa Residência Pedagógica uma oportunidade de mudar o cenário da Educação Básica do Distrito Federal, no que diz respeito à melhoria na formação inicial dos discentes de licenciatura. 
Infere-se também que os preceptores vinham achando o programa bastante positivo, dando enfoque aos projetos e outras dinâmicas realizadas nas escolas. Eles reforçam que presença dos residentes torna a escola um ambiente melhor de trabalho, seja auxiliando os próprios preceptores com atividades lúdicas e planejamentos, ou auxiliando os próprios estudantes.

$\mathrm{Na}$ visão de todos os preceptores, o Programa Residência Pedagógica auxilia positivamente na formação inicial dos discentes de Licenciatura da Universidade de Brasília. Esse auxílio vem de várias formas, porém, todos dão maior foco na experiência adquirida pelos residentes durante o programa, devido às horas de imersão nas escolas.

Além da formação inicial dos discentes de licenciatura, todos os preceptores conseguiram enxergar, no Programa Residência Pedagógica um processo de formação continuada o que os surpreendeu positivamente. Para os preceptores participar do Programa foi uma oportunidade para ter uma maior aproximação com a universidade, já que os residentes trazem muitas novidades, tanto para as suas aulas quanto para conversas informais que ocorrem durante o período de imersão.

Houve críticas e também algumas sugestões por parte dos preceptores, sendo as maiores o não esclarecimento de algumas informações e a falta de troca de experiências entre os subprojetos.

O presente trabalho mostra a visão dos preceptores, porém, é sugerido que trabalhos futuros investiguem também a visão dos coordenadores dos subprojetos e até mesmo os próprios residentes, para que assim o projeto seja, aos poucos, aprimorado. Para isso, é necessário reforçar a ideia de manter o projeto em andamento com a abertura de um novo edital. A abertura do Edital $n^{\circ} 1 / 2020$ da CAPES, que a UnB foi contemplada, permite que novas pesquisas sejam realizadas, ampliando o entendimento desse processo de formação inicial e continuada, tão rico e importante para todos os participantes e principalmente visando a melhoria da Educação Básica pública Brasileira. 


\section{Agradecimentos e apoio}

Agradecemos a todos os participantes da pesquisa e ao apoio da CAPES pelo financiamento do Programa Residência Pedagógica e às bolsas concedidas.

\section{Referências Bibliográficas}

AUAREK, Wagner; VISEU, Floriano. Formação inicial do professor de matemática para escolas do Campo: 'olhares' da comunidade campesina. Revemat: Revista Eletrônica de Educação Matemática, v. 12, n. 2, p. 247261, 2017.

BARDIN, Laurence. Análise de conteúdo. 3 ed. Lisboa: Edições 70. 2006.

BATISTA, Eliane Regina Martins; LIMA, Tânia Maria. Formação de professores no curso de pedagogia e o ensino de ciências. Revista Ensino de Ciências e Humanidades-RECH, v. 1, n. 1, Jul-Dez, p. 336-358, 2017.

BATISTA, Irinéa de Lourdes; LAVAQUI, Vanderlei; SALVI, Rosana Figueiredo. Interdisciplinaridade Escolar no Ensino Médio por Meio de Trabalho com Projetos Pedagógicos. Investigações em Ensino de Ciências, v. 13, n. 2, p. 209-239, 2016.

BEDIN, Everton; PINO, José Claudio. Sentimento docente sobre a prática pedagógica: reflexões e avaliações. Revista Brasileira de Ensino de Ciências e Tecnologias, v. 12, n. 2, p. 53-72, 2019.

BISCONSINI, Camila Rinaldi; OLIVEIRA, Amauri Aparecido Bássoli. A Prática como Componente Curricular na formação inicial de professores de Educação Física. Movimento (ESEFID/UFRGS), v. 24, n. 2, p. 455-470, 2018.

BISPO, Joelma Gomes de Oliveira; SOARES, Sandra Regina. O papel da escola básica na formação inicial de professores: representações de docentes universitários. Educação Unisinos, v. 21, n. 1, p. 81-89, 2017.

BRASIL. Lei de Diretrizes e Bases da Educação. Lei $\mathbf{N}^{\circ} \mathbf{9 . 3 9 4}$, de 20 de dezembro de 1996. Estabelece as Diretrizes e Bases da Educação Nacional. Disponível em: http://www.planalto.gov.br/ccivil_03/leis/19394.htm. Acesso em: 22 ago. 2019.

BRASIL. Conselho Nacional de Educação (Brasília). Resolução CNE/CP 2, de 19 de fevereiro de 2002. Institui a duração e a carga horária dos cursos de licenciatura, de graduação plena, de formação de professores da Educação Básica em nível superior. Diário oficial da união. Secção 1, p. 9.4 março 2002. Disponível em: http://portal.mec.gov.br/cne/arquivos/pdf/CP022002.pdf . Acesso em: 25 ago. 2019. 
BRASIL. Decreto no 7.219, de 24 de junho de 2010. Dispõe sobre o Programa Institucional de Bolsa de Iniciação à Docência - Pibid e dá outras providências. $\quad$ Brasília/DF. 2010. Disponível em: http://www.planalto.gov.br/ccivil 03/ Ato2007-2010/2010/Decreto/D7219.htm. Acesso em: 23 ago. 2019.

BRASIL. Lei $n^{\circ}$ 13.005, 25 de junho de 2014. Aprova o Plano Nacional de Educação - PNE e dá outras providências. Diário Oficial da União, Brasília, DF., 26 de junho de 2014. Disponível em: http://pne.mec.gov.br/18-planossubnacionais-de-educacao/543-plano-nacional-de-educacao-lei-n-13-005-2014. Acesso em: 11 nov. 2019.

BRASIL. Ministério da Educação. 2017. MEC lança Política Nacional de Formação de Professores com Residência Pedagógica. Disponível em: http://portal.mec.gov.br/busca-geral/211-noticias/218175739/55921-mec-lancapolitica-nacional-de-formacao-de-professores-com-80-mil-vagas-pararesidencia-pedagogica-em-2018. Acesso em: 22 ago. 2019.

BRASIL. Ministério da Educação. Edital CAPES $n^{\circ}$ 06/2018. Brasília, DF: Ministério da Educação, 01 de março, 2018. Assunto: Programa de Residência Pedagógica. Disponível em: https://www.capes.gov.br/images/stories/download/editais/01032018-Edital-62018-Residencia-pedagogica.pdf . Acesso em: 23 ago. 2019.

BRASIL. Ministério da Educação. Edital CAPES $\mathbf{n}^{\circ}$ 01/2020. Brasília, DF: Ministério da Educação, 01 de março, 2018. Assunto: Programa de Residência Pedagógica. Disponível em: https://capes.gov.br/images/novo portal/editais/editais/06012020-Edital-1-2020Residência-Pedagógica.pdf . Acesso em: 24 ago. 2019.

CORREA, Licinia Maria; CUNHA, Maria Amália de Almeida; ZANARDI, Teodoro; SILVA, Liliane Oliveira Palhares. Escola como locus da formação continuada e o Pacto Nacional pelo Fortalecimento do Ensino Médio: efeitos na vida dos professores. Em Aberto, v. 30, n. 98, p.87-104, 2017.

COSTA, Váldina Gonçalves. Professores Formadores do Curso de Licenciatura em Letras - EAD: Formação e Identidade. Revista Triângulo, v. 9, n. 1, p. 175-184, 2016.

COSTA, Jandira Gomes. Prática docente: As dificuldades dos professores nos centros de educação profissional no município de Santana no estado do Amapá. RACE-Revista da Administração, v. 3, p. 218-231, 2019.

CUNHA, Ana Maria de Oliveira; KRASILCHIK, Myriam. A formação continuada de professores de ciências: percepções a partir de uma experiência. In: $23^{a}$ REUNIÃO ANUAL DA ASSOCIAÇÃO NACIONAL DE PÓS-GRADUAÇÃO E PESQUISA EM EDUCAÇÃO. 2000, Caxambu. Anais [...]. Caxambu: 2000. ONLINE. Disponível em: https://anped.org.br/biblioteca/item/formacaocontinuada-de-professores-de-ciencias-percepcoes-partir-de-uma-experiencia. 
DOURADO, Luiz Fernandes. Diretrizes curriculares nacionais para a formação inicial e continuada dos profissionais do magistério da educação básica: concepções e desafios. Educação \& Sociedade, v. 36, n. 131, p. 299-324, 2015.

DUARTE, Rosália. Entrevistas em pesquisas qualitativas. Educar em revista, n. 24, p. 213-225, 2004.

ESTEVES, Rafael Reis; FONTANA, Bruna Rosso Bez; OLIVEIRA, Paula Telles; SILVA, Glauco Garcia Martins Pereira. Aplicação da gestão visual como ferramenta de auxílio para o gerenciamento de projetos de arquitetura e engenharia em uma universidade pública. Gestão e Projetos: GeP, v. 6, n. 3, p. 71-83, 2015.

FLORES, Maria Assunção. Algumas reflexões em torno da formação inicial de professores. Educação, v. 33, n. 3, p. 182-188, 2010.

FLORES, Maria Assunção. Escola e sala de aula: a liderança dos professores. Porto: Universidade Católica Editora, p. 31-54.

GATTI, Bernardete A. A formação inicial de professores para a educação básica: as licenciaturas. Revista USP, n. 100, p. 33-46, 2014.

HARRES, João Batista Siqueira; WOLFFENBUTTEL, Patrícia Pinto; DELORD, Gabriela Carolina Cattani. Um estudo exploratório internacional sobre o distanciamento entre a escola e a universidade no ensino de ciências. Investigações em Ensino de Ciências, v. 18, n. 2, p. 365-383, 2016.

HARTMANN, Ângela Maria; GOI, Mara Elisângela Jappe. O estágio no contexto da formação de professores: campo de experimentação e reflexão sobre a prática pedagógica. Revista Brasileira de Ensino de Ciência e Tecnologia, v. 12, n. 2, p. 122-147, 2019.

Instituto Nacional de Estudos e Pesquisas Educacionais Anísio Teixeira. Sinopse - Estatística da Educação Básica 2018. Brasília: Inep, 2019. Disponível em: http://portal.inep.gov.br/sinopses-estatisticas-da-educacaobasica. Acesso em: 01 set. 2019.

LEITE, Carlinda; PINTO, Carmem Lascano. O trabalho colaborativo entre os professores no quotidiano escolar: condições para a sua existência e sustentabilidade. Educação, Sociedade \& Culturas. n. 48, p. 69-91, 2016.

LIMA, Jorge Ávila; FIALHO, Adolfo. Colaboração entre professores e perceções da eficácia da escola e da dificuldade do trabalho docente. Revista Portuguesa de Pedagogia, v. 49, n.2, p. 27-53, 2015.

LOPES, Anemari Roesler Luersen Vieira, ARAUJO, Elaine Sampaio; CEDRO, Wllington Lima; MOURA, Manoel Oriosvaldo. Trabalho coletivo e organização do ensino de matemática: princípios e práticas. Zetetiké, v. 24, n. 1, p. 13-28, 2016 
MACHADO, Franciele Teixeira. Relações entre trabalho, qualidade de vida e saúde dos docentes. Revista da Sociedade Brasileira de Fonoaudiologia. v.12, n.1, p.18-22. 2007.

MARCHI, Miriam Ines; DA COSTA SILVA, Tânia Núsia. Formação continuada de professores: buscando melhorar e facilitar o ensino para deficientes visuais por meio de tecnologias assistivas. Revista Educação Especial, v. 29, n. 55, p. 457-469, 2016.

MARTINS, André Ferrer Pinto. Estágio supervisionado em física: o pulso ainda pulsa. Revista Brasileira de Ensino de Física, v. 31, n. 3, p. 34021-34027, 2009.

MELLO, Guiomar Namo. Formação inicial de professores para a educação básica: uma (re) visão radical. São Paulo em perspectiva, v. 14, n. 1, p. 98$110,2000$.

NASCIMENTO, Ivany Pinto; RODRIGUES, Sônia Eli Cabral. Representações sociais sobre a permanência na docência: o que dizem docentes do ensino fundamental? Educação e Pesquisa, v. 44, p. 1-16, 2018.

PACHECO, José Augusto. Formação de professores: teoria e Praxis. Instituto de Educaçao e Psicologia, Universidade do Minho, 1995

PIMENTA, Selma Garrido. Formação de professores: saberes da docência e identidade do professor. Revista da Faculdade de Educação, v. 22, n. 2, p. 72-89, 1996.

PIRES, José Carlos Miranda; RODRIGUES, Amabia Firmino; FEITOSA, Edinilza Maria Anastácio; SOUSA, Julyane Moreira de; SANTOS, Luiz Eduardo Torres dos; ARAÚJO, Nicole Lopez da Silva. Investigação sobre a importância do estágio e do Pibid para formação docente dos alunos do curso de licenciatura em química da FACEDI/UECE. Blucher Chemistry Proceedings, v. 3, n. 1, p. 138-147, 2015.

QUADROS, Vera Cristina; KOCHHANN, Maria Elizabete Rambo. Contribuições do Estágio Curricular Supervisionado da Licenciatura em Matemática no Processo de construção dos Saberes Docentes dos Estagiários. Revista de Ensino de Ciências e Matemática, v. 9, n. 3, p. 106-122, 2018.

RODRIGUES, Silvia Adriana; GARMS, Gilza Maria Zauhy. Relação professoraluno e afetividade: reflexões wallonianas sobre o ambiente de aprendizagem e a prática docente Série-Estudos-Periódico do Programa de Pós-Graduação em Educação da UCDB. n. 23, p.31-41, 2013.

SANTOS, Elaine Fernanda; VIEIRA, Mayane Santos; SANTOS, Sindiany Suelen Caduda. Ser Professor/a: A Importância da Prática Pedagógica do Estágio Supervisionado no Ensino de Ciências, Aracaju/SE. In: ENCONTRO INTERNACIONAL DE FORMAÇÃO DE PROFESSORES E FÓRUM PERMANENTE DE INOVAÇÃO EDUCACIONAL , 2018 Aracaju, Anais [...]. Aracaju, 2018. ONLINE. 
SCALABRIN, Izabel Cristina; MOLINARI, Adriana Maria Corder. A importância da prática do estágio supervisionado nas licenciaturas. Revista Científica, Araras, v. 7, n. 1, p. 1-12, 2013.

SECCO, Daiane; REBEQUE, Paulo Vinícius; SOUZA, J. Análise da evolução dos projetos pedagógicos de um curso de formação inicial de professores de Física. TEAR: Revista de Educação, Ciência e Tecnologia. v. 6, n. 2, p. 1-21, 2017.

SILVA, Delano Moody Simões.; PEDREIRA, Ana Júlia. Expectativas e medos de professores em formação: o papel do estágio supervisionado de ensino. Ensino em Re-Vista, v. 27, p. 118-137, 2020.

SILVA, Rafael Rodrigues; TEIXEIRA, Maria Rafaela Soares; RODRIGUES, Flavia Tatiane Ribeiro de Lima. Uma análise da gestão de projetos de extensão de uma Instituição Federal de ensino. Revista de Gestão e Secretariado, v. 7, n. 3, p. 150-171, 2016.

SILVA, Rodrigo Barbosa; OLIVEIRA, Antonia Silva. O Estágio Supervisionado nos Cursos de Formação de Professores: Decisão Quanto ao Futuro Profissional. Humanidades \& Inovação, v. 3, n. 1, p. 7-16, 2016.

TREVISAN, Daniele; BERNARDI, Luci Teresinha Marchiori dos Santos; CECCO, Bruna Larissa; MENEZES, Daiane. PIBID e a formação do professor de matemática: experiências de inovação e interdisciplinaridade. In: XII ENCONTRO NACIONAL DE EDUCAÇÃO MATEMÁTICA, EDUCAÇÃO MATEMÁTICA NA CONTEMPORANEIDADE: DESAFIOS E POSSIBILIDADES, 15., 2016, São Paulo. Anais [...]. São Paulo, 2016. ONLINE.

VIEIRA, Márcia; BAPTISTA, B. A utilização das Tecnologias da Informação e Comunicação nos projetos educacionais interdisciplinares. In: WORKSHOP DE INFORMÁTICA NA ESCOLA, 2015, Anais [...]. 2015. ONLINE.

VILELA, Naiara Sousa; MELO, Geovana Ferreira. A contribuição do feedback para a avaliação da aprendizagem no contexto universitário. In: $3^{\circ}$ SIMPÓSIO AVALIAÇÃO DE EDUCAÇÃO SUPERIOR, 5. 2017, Florianópolis. Anais [...]. 2017. ONLINE.

\section{Sobre os autores}

\section{Farah Camila Murtadha}

murtadhabiologia@gmail.com

Licenciada em Ciências Biológicas pela Universidade de Brasília e Mestranda em Bioquímica pelo programa de Patologia Molecular da Faculdade de Medicina da Universidade de Brasília. 


\section{Ana Júlia Pedreira}

anajuliapedreira@unb.br

Doutora em Educação e Professora do Núcleo de Educação Científica do Instituto de Biologia da Universidade de Brasília. Professora e Orientadora do Programa de Mestrado Profissional do Ensino de Biologia - PROFBIO/UnB e do Programa de Pós Graduação de Educação em Ciências/ UnB. 